\title{
Trajectory modelling of ambulatory care sensitive conditions in Finland in 1996- 2013: assessing the development of equity in primary health care through clustering of geographic areas - an observational retrospective study
}

Markku Satokangas ${ }^{1,2,3^{*}}$ (D), Sonja Lumme ${ }^{1}$, Martti Arffman ${ }^{1}$ and IImo Keskimäki ${ }^{1,4}$

\begin{abstract}
Background: Due to stagnating resources and an increase in staff workload, the quality of Finnish primary health care (PHC) is claimed to have deteriorated slowly. With a decentralised PHC organisation and lack of national stewardship, it is likely that municipalities have adopted different coping strategies, predisposing them to geographic disparities. To assess whether these disparities emerge, we analysed health centre area trajectories in hospitalisations due to ambulatory care sensitive conditions (ACSCs).

Methods: ACSCs, a proxy for PHC quality, comprises conditions in which hospitalisation could be avoided by timely care. We obtained ACSCs of the total Finnish population aged $\geq 20$ for the years 1996-2013 from the Finnish Hospital Discharge Register, and divided them into subgroups of acute, chronic and vaccine-preventable causes, and calculated annual age-standardised ACSC rates by gender in health centre areas. Using these rates, we conducted trajectory analyses for identifying health centre area clusters using group-based trajectory modelling. Further, we applied arealevel factors to describe the distribution of health centre areas on these trajectories.

(Continued on next page)
\end{abstract}

\footnotetext{
*Correspondence: markku.satokangas@thl.fi

This Abstract was previously published and presented at the 11th European Public Health Conference in November 2018 [1].

'Social and Health Systems Research Unit, National Institute for Health and Welfare, P.O. Box 30, 00271 Helsinki, Finland

${ }^{2}$ Department of General Practice and Primary Health Care, Network of

Academic Health Centres, University of Helsinki, Helsinki, Finland

Full list of author information is available at the end of the article
}

(c) The Author(s). 2019 Open Access This article is distributed under the terms of the Creative Commons Attribution 4.0 International License (http://creativecommons.org/licenses/by/4.0/), which permits unrestricted use, distribution, and reproduction in any medium, provided you give appropriate credit to the original author(s) and the source, provide a link to the Creative Commons license, and indicate if changes were made. The Creative Commons Public Domain Dedication waiver (http://creativecommons.org/publicdomain/zero/1.0/) applies to the data made available in this article, unless otherwise stated. 
(Continued from previous page)

Results: Three trajectories - and thus separate clusters of health centre areas - emerged with different levels and trends of ACSC rates. During the study period, chronic ACSC rates decreased (40-63\%) within each of the clusters, acute ACSC rates remained stable and vaccine-preventable ACSC rates increased (1-41\%). While disparities in rate differences in chronic ACSC rates between trajectories narrowed, in the two other ACSC subgroups they increased. Disparities in standardised rate ratios increased in vaccine-preventable and acute ACSC rates between northern cluster and the two other clusters. Compared to the south-western cluster, 13-16\% of health centre areas, in rural northern cluster, had 47-92\% higher ACSC rates - but also the highest level of morbidity, most limitations on activities of daily living and highest PHC inpatient ward usage as well as the lowest education levels and private health and dental care usage.

Conclusions: We identified three differing trajectories of time trends for ACSC rates, suggesting that the quality of care, particularly in northern Finland health centre areas, may have lagged behind the general improvements. This calls for further investments to strengthen rural area PHC.

Keywords: Development of health equity, Ambulatory care sensitive conditions, Primary care, Inpatient hospitalisation, Group-based trajectory modelling

\section{Background}

In recent decades, Finnish public primary health care (PHC) has been suspected of slowly deteriorating - especially if compared to other sectors of the Finnish health care system, i.e. specialist care and occupational and private health care. In the absence of systematic PHC performance and quality indicators, this argument has been based on statistics regarding long waiting times [1], stagnating financial resources [2], stagnating numbers of both physicians and other personnel [3], a decrease in the number of GP consultations [4] and an increase in GP job strain and workload $[1,5]$. This situation has persisted, although improving access to and quality of $\mathrm{PHC}$ has been referred to among the main policy measures in reducing Finnish health inequities [6]. As PHC has been found to reduce the ill effects of income inequality on health [7], the suspected deterioration could eventually have a negative impact on the already existing health inequities in Finland [8]. We found internationally no paper that would present a comprehensive approach to assess - and either to support or contradict - this kind of argument of PHC deterioration over time.

Whether or not this deterioration exists, in comparison to most European countries Finland has a strong, nationwide public PHC funded through taxes and operating on the principle of universal access [9]. Unlike in the other Nordic countries, Finland has lower number of physicians than the EU average - over third of them GPs [10]. The number of nurses is high as in the other Nordic countries. Though Finns have the EU average of life-expectancy and good perceived health, they also report one of the EUs highest proportions with chronic conditions and disabilities [10]. Finnish PHC acts as a gatekeeper to specialist care, which takes place mainly in public hospitals. Further, a hospital serves mainly geographically nearby municipalities in its hospital district. The national level of avoidable hospital admissions for five chronic conditions is slightly lower than the EU average [10]. The nationwide network of municipal health centres, the foundation of the Finnish public PHC was built in the 1970s, funded with state subsidies earmarked to PHC [11]. However, amidst the difficult recession in the early 1990s the state's economic control over PHC services was abolished: the level of state subsidies was reduced and their earmarking was removed [1]. Simultaneously, the funding of specialist care was to be decided between municipalities, joint municipal authorities and hospital districts [11]. While funding both $\mathrm{PHC}$ and specialist care, individual municipalities have had increased autonomy in terms of organising and financing the first, but only minor control over the organising and the expenditures of the latter. Since these changes, specialist care has been able to secure its funding and its attractiveness as an employer, while municipal PHC has had to endure cost savings. After recovering from the recession, Finland has had a continuous physician shortage, with PHC having the least favourable position to compete for the workforce. In 2013 PHC in Finland, with approximately 5.4 million inhabitants, was organised independently in 89 municipalities and through 62 joint municipal authorities in the rest of the 215 municipalities. Due to this decentralisation and a lack of national stewardship with respect to PHC, it is likely that the stagnation of resources and strategies for coping with it have differed between municipalities. Thus, if the suspected deterioration exists, it might present itself in the form of increasing geographic health inequities - thus challenging the achievement of the national goal of health equity [12]. This necessitates the assessment of Finnish PHC performance by analysing over time geographic distribution in health quality outcomes.

This study aimed to identify any clusters of geographic areas where performance of PHC either develops clearly 
better or worse than elsewhere in Finland. To achieve this, we assessed over time the geographical distribution of Ambulatory Care Sensitive Condition (ACSC) rates in Finland for the years 1996-2013 using group-based trajectory modelling (GBTM). This approach to analyse geographic disparities distributes health centre areas (individual municipalities or joint municipal authorities) to trajectories, depending on the level and development of ACSC rates in these areas. The use of GBTM allowed us to identify homogenous clusters of developmental trajectories of ACSC rates by areas [13]. Further, we describe this distribution with area-level factors. These include health-care-dependant factors, the socioeconomic characteristics of the population, municipal characteristics and other health-related factors. Our hypothesis was that the suspected slow deterioration of PHC, due to decentralisation and a lack of national stewardship, would present itself as a geographical polarization of the health of the population between municipalities. Further, we hypothesised that the increasing proportion of elderly people, number of GP consultations and persons in a low socioeconomic position (SEP), as well as elevated morbidity or limitations in activities of daily living (ADL), would associate with an increased level of ACSC rates. There is a clear geographic inequity in morbidity among Finns, which we assumed to affect the ACSC rates: population of southern Finland is healthier than population of the eastern and northern Finland [14]. To the best of our knowledge no previous study has applied GBTM to analyse the geographical clustering of over time development of ACSC rates.

\section{Methods}

\section{Data collection}

To explore the extent of geographic variation and its temporal development in $\mathrm{PHC}$, this retrospective observational study utilised routinely collected hospitalisation data to assess trajectories for ACSCs. This proxy indicator of PHC quality and performance is comprised of the conditions under which hospitalisations could possibly be prevented via the timely function of PHC. No single, universal list of ACSC conditions exists internationally as hospitalisation criteria vary between countries and health care systems [15]. As Finland has no validated list of ACSC conditions (for example through a Delphi process [16]), we applied its UK definition to maintain some international comparability [17]. However, eventual abandoning of ICD-9 codes from Finnish hospitalisation data in 2011 (previously alongside the ICD-10 codes) resulted in systematic drop of ACSC levels. This occurred due to unspecified pneumonia (J18.9), which was included before 2011 as it converts into the same Finnish ICD-9 code (485) as the diagnose J18.8 included in the UK definition. We chose to include J18.9 to maintain backward compatibility. In preliminary analyses, this single diagnosis covered three-fourths of all pneumonia hospitalisations [data not shown].

We obtained data on the hospitalisations due to ACSCs for the total Finnish population aged $\geq 20$ for the years 1996-2013 from the Finnish Hospital Discharge Register, maintained by the National Institute for Health and Welfare (THL). To account for hospital transfers, we combined two consecutive ACSC hospitalisations (separated by only 1 day) to a single hospitalisation with the diagnose of the first one. To cover different preventive strategies, as proposed by previous studies [18, 19], we subcategorised the ACSC hospitalisations as either acute, chronic or vaccine-preventable (Additional file 1) [20]. Further, we analysed these subgroups by gender and geographic areas due to different levels and disease patterns of ACSCs in men and women [21]. The applied area unit was health centre areas: a total of 131 geographical areas, which represented either a single municipality or a consolidation of 2-8 small municipalities. In the latter case, PHC was organised by a joint authority running the local health centre organisation. Populations in these areas varied between 5200 and 612,700, with a median population of 22,600 in 2013 .

We chose to include area-level descriptive factors, which have been suggested in previous studies assessing ACSCs, such as SEP [18], morbidity [22] and limitations in ADL [23]. Also, we included factors related to the usage of and access to PHC as well as factors describing the structure of municipalities - as these might be associated with some of the geographic differences in ACSC distribution. Table 1 summarises the included descriptive factors, which were collected annually for 19962013 from Sotkanet.fi, a Statistics and Indicator Bank maintained by THL [24] - expect for the pensioner's care allowance which was collected from the Kelasto.fi, a statistical database maintained by the Social Insurance Institution of Finland [25]. The Research Ethics Committee of the National Institute for Health and Welfare provided ethical consent for the study.

\section{Statistical analysis}

We calculated annual age-standardised rates/100,000 person years in health centre areas by applying the direct method of standardisation and the European Standard Population [26]. No missing data or small cells existed within the age-standardised rates. To assess the development and clustering of these rates in the health centre areas, we applied group-based trajectory modelling [27]. In other words, with this modelling we identified health centre areas and grouped them into separate clusters according to the similarity of both their level and development of ACSC rates. The purpose of the analysis was to identify different developmental paths of ACSC rates 
Table 1 Area-level descriptive factors by their level of analysis

\begin{tabular}{|c|c|}
\hline List of variables & Comments \\
\hline \multicolumn{2}{|l|}{ Health care-dependant factors } \\
\hline \multicolumn{2}{|l|}{$\begin{array}{l}\text { GP consultations per } 1000 \\
\text { inhabitants }\end{array}$} \\
\hline \multicolumn{2}{|l|}{$\begin{array}{l}\text { Primary and secondary care } \\
\text { expenditures }\end{array}$} \\
\hline \multicolumn{2}{|l|}{$\begin{array}{l}\text { Inpatient PHC periods per } 1000 \\
\text { inhabitants }\end{array}$} \\
\hline \multicolumn{2}{|l|}{$\begin{array}{l}\text { Specialised somatic inpatient } \\
\text { care periods per } 1000 \\
\text { inhabitants }\end{array}$} \\
\hline \multicolumn{2}{|l|}{$\begin{array}{l}\text { Dentist visits in health centres } \\
\text { per } 1000 \text { inhabitants }\end{array}$} \\
\hline \multicolumn{2}{|l|}{$\begin{array}{l}\text { Reimbursed private dental care } \\
\text { visits per } 1000 \text { inhabitants }\end{array}$} \\
\hline \multicolumn{2}{|l|}{$\begin{array}{l}\text { Proportion of inhabitants } \\
\text { reimbursed for private health } \\
\text { care use }\end{array}$} \\
\hline \multicolumn{2}{|c|}{ Sociodemographic characteristics of the populations } \\
\hline \multicolumn{2}{|l|}{$\begin{array}{l}\text { Proportions of inhabitants aged } \\
\geq 65\end{array}$} \\
\hline \multicolumn{2}{|l|}{$\begin{array}{l}\text { Ratio of people aged }<15 \\
\text { and }>64 \text { to every hundred } \\
\text { people aged 15-64 }\end{array}$} \\
\hline \multicolumn{2}{|l|}{$\begin{array}{l}\text { Proportion of inhabitants with a } \\
\text { tertiary education }\end{array}$} \\
\hline \multicolumn{2}{|l|}{$\begin{array}{l}\text { Average years of education after } \\
\text { primary education }\end{array}$} \\
\hline \multicolumn{2}{|l|}{$\begin{array}{l}\text { Proportion of low-income } \\
\text { households }\end{array}$} \\
\hline \multicolumn{2}{|l|}{$\begin{array}{l}\text { Proportion of inhabitants } \\
\text { receiving basic social assistance }\end{array}$} \\
\hline \multicolumn{2}{|l|}{$\begin{array}{l}\text { Ratio of unemployed to total } \\
\text { workforce }\end{array}$} \\
\hline \multicolumn{2}{|l|}{ Municipal characteristics } \\
\hline Type of municipality & $\begin{array}{l}\text { Either an individual municipality or } \\
\text { a consolidation of municipalities }\end{array}$ \\
\hline \multicolumn{2}{|l|}{$\begin{array}{l}\text { Proportion of inhabitants in the } \\
\text { largest municipality }\end{array}$} \\
\hline \multicolumn{2}{|l|}{ Degree of urbanisation } \\
\hline \multicolumn{2}{|l|}{ Other health-related factors } \\
\hline \multicolumn{2}{|l|}{ Potential years of life lost } \\
\hline $\begin{array}{l}\text { Pensioner's care allowance of } \\
\text { recipients aged } \geq 65 \text { per } 1000 \\
\text { inhabitants of the same age }\end{array}$ & $\begin{array}{l}\text { Used as a proxy for both morbidity } \\
\text { and limitations in } A D L \text {, as these are } \\
\text { the main requirements for the } \\
\text { allowance. }\end{array}$ \\
\hline THL's morbidity index & $\begin{array}{l}\text { Comprises cancer, coronary heart } \\
\text { disease, cerebrovascular diseases, } \\
\text { musculoskeletal diseases, mental } \\
\text { health problems, accidents and } \\
\text { dementia [14]. }\end{array}$ \\
\hline
\end{tabular}

between health centre areas which might go unnoticed with other statistical methods. With a multi-trajectory model, we analysed the distribution of the rates of three
ACSC subgroups (acute, chronic and vaccine-preventable conditions) simultaneously within a single model [28]. The goodness-of-fit of the trajectory models was tested using Bayesian information criterion (BIC) [29]. Based on this approach, we chose models against the alternative ones where the evidence was "very strong" (BIC difference $>10$ ) favouring the chosen trajectory models. Further, we calculated standardised rate ratios (SRRs) and rate differences (RDs) for these clusters of health centre areas. We tested the changes in annual trends of SRRs and RDs with linear regression model. Further, we analysed whether over time the development of area-level factors over time would associate with the distribution of health centre areas in the trajectories using an autoregressive Generalized Estimating Equation (GEE) model [30]. In other words, we tested whether any of these area-level factors had similar developments within a group of health centre areas over time along a single trajectory and that the finding was consistent for each of the trajectories. The differences of group averages in area-level descriptive factors between clusters were tested with ANOVA. The statistical analyses were performed using the TRAJ [31] and GEE procedures of the SAS system for Windows, release version 9.3 (SAS Institute, Cary, NC). The results were then combined with spatial information from Statistics Finland [32] using ArcGIS for Windows, release version 10.3.1 (Environmental Systems Research Institute, Redlands, CA).

\section{Results}

Altogether, we identified 123,975 hospitalisations due to ACSCs in 1996, and 99,684 in 2013. Overall, the total ACSC rates decreased throughout the country, mainly due to a reduction in chronic ACSC rates. The vaccinepreventable ACSC rates slightly increased. In 1996 the vaccine-preventable $\mathrm{ACSC}$ rate in men for the whole country was 1070 per 100,000 person years, and 1100 in 2013. The corresponding chronic ACSC rates were 3470 in 1996 and 1280 in 2013; and acute ACSC rates 820 in 1996 and 680 in 2013. In women the corresponding values were: for vaccine-preventable ACSC rates 490 in 1996 and 610 in 2013; for chronic ACSC rates 2240 in 1996 and 950 in 2013; and for acute ACSC rates 670 in 1996 and 650 in 2013. The annual means and ranges of ACSC rates in health centre areas are presented in Additional file 2. Women had lower ACSC rates than men for chronic and vaccine-preventable ACSC, while the acute ACSC rates were rather similar. The disparities in annual trends of RDs and SRRs between genders diminished $(p<0.0001)$ from 1996 to 2013 (Table 2).

In trajectory modelling, the applied multifactorial approach consisted of the rates of all three ACSC subgroups separately for both genders. In the model with the best goodness-of-fit, three trajectories (i.e. separate 
Table 2 Gender disparities that favoured women in ACSC rates in Finland

\begin{tabular}{|c|c|c|c|c|}
\hline \multirow[b]{2}{*}{ ACSC rates } & \multicolumn{2}{|l|}{ SRR [CI 95\%] } & \multicolumn{2}{|l|}{ RD [Cl 95\%] } \\
\hline & 1996 & 2013 & 1996 & 2013 \\
\hline Vaccine-preventable & 2.17 [2.10-2.23] & $1.81[1.77-1.85]$ & 577 [552-602] & 492 [472-512] \\
\hline Chronic & 1.55 [1.53-1.57] & $1.35[1.32-1.38]$ & 1227 [1184-1270] & 331 [308-353] \\
\hline Acute & 1.22 [1.19-1.25] & 1.05 [1.02-1.08] & 148 [127-168] & $32[15-48]$ \\
\hline
\end{tabular}

[Legend] The decrease in disparities in the annual trends of RDs and SRRs were statistically significant $(p$-value $<0.0001)$ in every subgroup

$S R R=$ standardised rate ratios

$R D=$ rate difference $(\mathrm{RD})$

clusters of health centre areas) emerged as health centre areas differed in terms of their levels and rates of change for ACSC rates (Fig. 1 and Additional file 2). The distribution of health centre areas in the trajectories was similar between genders - only slight differences arose. The trajectory with the highest level of ACSC rates comprised $13 \%$ of health centre areas for men and $16 \%$ for women, mainly in rural parts of northern Finland (i.e. northern cluster). The health centre areas (respectively 42 and 34\%) in the central parts of Finland (i.e. central cluster) had a lower level of ACSC rates in every subgroup than those in the northern cluster, and those (45 and 50\%) in south-western Finland (i.e. south-western cluster) had the lowest. Further, the northern cluster had $6 \%$ of the total Finnish male population and $7 \%$ of the female population, while the proportions in the central cluster were 39 and $32 \%$, and in the south-western cluster 55 and 61\%, respectively.

In 1996-2013, we observed increasing disparities in annual trends of RDs $(p \leq 0.0012)$ in vaccine-preventable ACSC rates between the northern cluster and both the central and the south-western clusters. The increase of vaccine-preventable ACSC rates in men were: $14 \%$ in the northern cluster, $1 \%$ in the central cluster and $4 \%$ in the south-western cluster in men and respectively 41, 23 and $21 \%$ in women. The disparities in annual trends of SRRs in vaccine-preventable ACSC rates increased in men $(p \leq 0.0129)$ but were not significant in women. The main conditions behind this increase were bacterial pneumonia and influenza [data not shown]. Though the disparities in annual trends of RDs decreased between all three clusters in chronic ACSC $(p<0.0001)$, the annual trends in SRRs were similar between clusters (rates increased $62-63 \%$ in men and $40-45 \%$ in women).

In acute ACSC rates, the annual trends of SRRs and RDs increased in the favour of central and the south-western clusters $(p \leq 0.0002$ and $p \leq 0.0006$ respectively): while their rates decreased $(16-17 \%$ in men and 4-5\% in women), those of the northern cluster either decreased less (7\% in men) or increased (21\% in women). By examining the hospitalisations for individual conditions, we traced this difference to both dental conditions and kidney and urinary tract infections. The increase in these conditions was higher in the northern cluster than elsewhere [data not shown].

Overall, the disparities in RDs between the northern cluster and the other two clusters decreased with chronic ACSC rates but increased with vaccine-preventable and acute ACSC rates. The respective disparities in SRRs remained unchanged in chronic ACSC rates, but increased in vaccine-preventable ACSC rates in men and in acute ACSC rates in both genders. When comparing the central and the south-western clusters, disparities in SRRs and RDs remained rather similar, with the exception of decreasing disparities in RDs in chronic ACSC rates (Table 3 ).

All the descriptive area-level factors correlated quite strongly with each other. When estimated using GEE, the factors that significantly associated with the distribution of health centre areas in the trajectories for both genders were as follows: increase in morbidity index $(p \leq 0.033)$, number of inpatient PHC periods $(p \leq 0.0002)$ and number of pensioner's care allowance of recipients aged $\geq 65$ $(p \leq 0.0038)$ associated with the higher likelihood that health centre area was allocated to cluster with higher ACSC rates (i.e. northern cluster). Further, increase in proportion of both inhabitants aged $\geq 65(p<0.0001)$ and with tertiary education $(p \leq 0.0381)$ and proportion of inhabitants reimbursed for private health care use ( $p \leq$ 0.0203) associated with the higher likelihood that health centre area was allocated to cluster with lower ACSC rates (i.e. southwestern cluster). Two factors were significant for women only: the increase in number of reimbursed private dental care visits $(p=0.0005)$ associated with the higher likelihood that health centre area was allocated to cluster with higher ACSC rates and the increase in municipal degree of urbanisation $(p=0.0295)$ associated with the higher likelihood that health centre area was allocated to cluster with lower ACSC rates. No other area-level factors improved the model. The health centre areas in the northern cluster were characterised by low SEP, less usage of private health and dental care, and a lower degree of urbanisation, as well as high morbidity, limitations in ADL among the elderly and a greater number of inpatient $\mathrm{PHC}$ periods (Table 4). The findings were the opposite for the south-western cluster. The central cluster had the highest proportion of inhabitants aged $\geq 65$. 


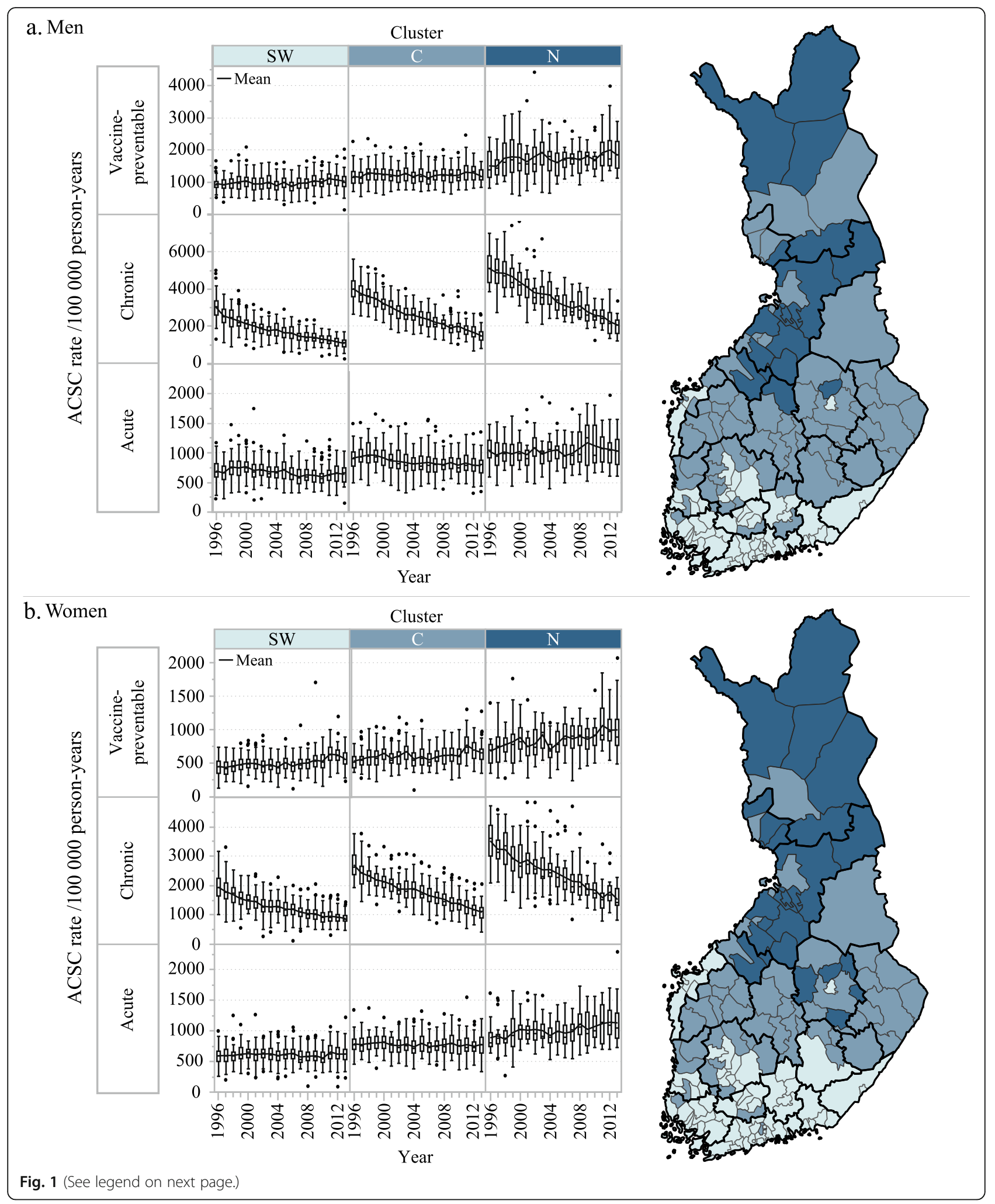


(See figure on previous page.)

Fig. $1 \mathbf{a}$ and $\mathbf{b}$ Allocation of Finnish health centre areas to clusters by their ACSC rates with trajectory modelling. Health centre areas allocated to a single cluster share the similar level and development of age-standardized rates (per 100,000 person-years) of three subgroups of ambulatory care sensitive conditions (ACSCS) in 1996-2013. Box and whisker plots represent the distribution (the median, interquartile range, interquartile range $\times 1.5$ and outliers) of these rates between health centre areas based on each ACSC subgroup, cluster and year. Note the different ranges of $y$-axis between subgroups and genders. The health centre areas in the map are coloured by the clusters they were allocated to, while thicker black lines mark the borders of hospital districts. SW = southwestern cluster, $\mathrm{C}=$ central cluster, $\mathrm{N}=$ northern cluster. Adapted and built on the municipality based statistical units, Statistics Finland [32]. The material was downloaded from Statistics Finland's interface service on 6 October 2017 with the license CC BY 4.0

\section{Discussion}

We observed the geographical distribution of ACSC rates and their development over time in Finnish health centre areas in the years 1996-2013. Further, we differentiated three clusters of health centre areas using trajectories based on the level and development of ACSC rates of these areas and assessed whether the chosen area-level factors would describe this distribution in specific trajectories. Our findings illustrate increasing absolute and relative geographical disparities in vaccine-preventable and acute ACSC rates: the rates in the northern cluster were constantly the highest, but they also increased over time unlike in the other areas. This partially supports the suspected deterioration in PHC. Relative disparities in chronic ACSC rates remained unaffected, though the rates and absolute disparities decreased by almost two-thirds

Table 3 Comparison of ambulatory care sensitive condition rates by subgroups and between clusters in Finland

\begin{tabular}{|c|c|c|c|c|c|c|c|}
\hline \multirow{2}{*}{ Compared clusters } & & \multicolumn{2}{|c|}{ Vaccine-preventable } & \multicolumn{2}{|l|}{ Chronic } & \multicolumn{2}{|l|}{ Acute } \\
\hline & & 1996 & 2013 & 1996 & 2013 & 1996 & 2013 \\
\hline \multicolumn{8}{|l|}{ Men } \\
\hline & SRR & $1.61(1.48-1.74)$ & $1.77(1.67-1.87)$ & $1.84(1.77-1.92)$ & $1.91(1.81-2.01)$ & $1.47(1.35-1.59)$ & $1.61(1.50-1.73)$ \\
\hline \multirow[t]{3}{*}{$N$ to SW } & Rate & $1530 / 950$ & $1750 / 990$ & $5210 / 2820$ & 1980/1030 & $1030 / 700$ & $960 / 590$ \\
\hline & $\mathrm{RD}$ & $580(460-700)$ & $760(670-850)$ & $2380(2190-2580)$ & $940(840-1040)$ & $330(250-410)$ & $360(300-430)$ \\
\hline & SRR & $1.33(1.23-1.44)$ & $1.51(1.43-1.60)$ & $1.29(1.24-1.35)$ & $1.32(1.25-1.39)$ & $1.11(1.02-1.21)$ & $1.25(1.16-1.34)$ \\
\hline \multirow[t]{3}{*}{$\mathrm{N}$ to $\mathrm{C}$} & Rate & $1530 / 1150$ & $1750 / 1160$ & $5210 / 4020$ & $1980 / 1500$ & 1030/930 & $960 / 770$ \\
\hline & $\mathrm{RD}$ & $380(260-500)$ & $600(500-690)$ & 1190 (990-1380) & $480(380-570)$ & $100(20-190)$ & $190(120-260)$ \\
\hline & SRR & $1.21(1.15-1.26)$ & $1.17(1.13-1.21)$ & $1.42(1.39-1.46)$ & $1.45(1.41-1.50)$ & $1.32(1.26-1.38)$ & $1.29(1.25-1.35)$ \\
\hline \multirow[t]{2}{*}{ C to SW } & Rate & $1150 / 950$ & $1160 / 990$ & $4020 / 2820$ & $1500 / 1030$ & $930 / 700$ & $770 / 590$ \\
\hline & $\mathrm{RD}$ & $200(150-240)$ & $170(130-200)$ & $1200(1120-1270)$ & $470(430-500)$ & $220(190-260)$ & $170(150-200)$ \\
\hline \multicolumn{8}{|l|}{ Women } \\
\hline & SRR & $1.52(1.41-1.64)$ & $1.76(1.67-1.87)$ & $1.92(1.86-1.99)$ & $1.83(1.75-1.91)$ & $1.48(1.39-1.58)$ & $1.89(1.78-2.00)$ \\
\hline \multirow[t]{3}{*}{$N$ to SW } & Rate & $690 / 450$ & $970 / 550$ & $3520 / 1830$ & $1490 / 820$ & $860 / 580$ & $1050 / 550$ \\
\hline & $\mathrm{RD}$ & $240(190-290)$ & $420(370-470)$ & $1690(1580-1800)$ & $680(610-740)$ & $280(230-340)$ & $490(430-550)$ \\
\hline & SRR & $1.31(1.21-1.41)$ & $1.50(1.41-1.59)$ & $1.30(1.26-1.35)$ & $1.39(1.33-1.46)$ & $1.10(1.03-1.17)$ & $1.38(1.30-1.47)$ \\
\hline \multirow[t]{3}{*}{$\mathrm{N}$ to $\mathrm{C}$} & Rate & $690 / 530$ & $970 / 650$ & $3520 / 2710$ & $1490 / 1070$ & $860 / 790$ & $1050 / 760$ \\
\hline & $\mathrm{RD}$ & $160(110-210)$ & $320(270-380)$ & $820(700-930)$ & $420(350-490)$ & $80(20-130)$ & $290(230-350)$ \\
\hline & SRR & $1.16(1.11-1.22)$ & $1.18(1.14-1.22)$ & $1.48(1.45-1.51)$ & $1.31(1.27-1.35)$ & $1.35(1.30-1.41)$ & $1.37(1.32-1.42)$ \\
\hline \multirow[t]{2}{*}{ C to SW } & Rate & $530 / 450$ & $650 / 550$ & 2710/1830 & 1070/820 & $790 / 580$ & $760 / 550$ \\
\hline & $\mathrm{RD}$ & $70(50-100)$ & $100(80-120)$ & 870 (820-930) & $250(230-280)$ & $210(180-230)$ & $200(180-230)$ \\
\hline
\end{tabular}

The increase in disparities in annual trends of RDs was significant between the northern cluster and the other two clusters in vaccine-preventable ACSC rates and acute ACSC rates. In chronic ACSC rates the decrease of these disparities was significant between all three clusters. The increase in disparities in annual trends of SRRs was significant between the northern cluster and both of the two other clusters in vaccine-preventable ASCS rates in men and acute ACSC rates in both genders. The ACSC rates presented were calculated from the total population of each of the clusters and thus differ from the mean rates of health centre areas presented in Additional file 2

SW = southwestern cluster

$C=$ central cluster

$N=$ northern cluster

$S R R=$ standardised rate ratios (and their 95\% clearance intervals)

Rate $=$ age-standardized rates $/ 100,000$ person-years

$R D=$ rate differences (and their 95\% clearance intervals) 
Table 4 Characteristics of area-level factors in health centre areas by clusters in 1996-2013 (mean \pm SE)

\begin{tabular}{|c|c|c|c|c|c|c|}
\hline \multirow[b]{2}{*}{ Clusters } & \multicolumn{3}{|l|}{ Men } & \multicolumn{3}{|c|}{ Women } \\
\hline & SW & C & $\mathrm{N}$ & SW & C & $\mathrm{N}$ \\
\hline Health centre areas (n) & 59 & 55 & 17 & 65 & 45 & 21 \\
\hline \multicolumn{7}{|l|}{ Healthcare-dependant factors } \\
\hline Inpatient primary health care periods per 1000 inhabitants & $\begin{array}{l}30 \\
\pm 0.5\end{array}$ & $\begin{array}{l}70 \\
\pm 1.1\end{array}$ & $\begin{array}{l}98 \\
\pm 2.4\end{array}$ & $\begin{array}{l}43 \\
\pm 0.7\end{array}$ & $\begin{array}{l}92 \\
\pm 1.4\end{array}$ & $\begin{array}{l}114 \\
\pm 2.5\end{array}$ \\
\hline Reimbursed private dental care visits per 1000 inhabitants & $\begin{array}{l}460 \\
\pm 6\end{array}$ & $\begin{array}{l}290 \\
\pm 5\end{array}$ & $\begin{array}{l}210 \\
\pm 6\end{array}$ & $\begin{array}{l}450 \\
\pm 6\end{array}$ & $\begin{array}{l}270 \\
\pm 6\end{array}$ & $\begin{array}{l}210 \\
\pm 6\end{array}$ \\
\hline Proportion of people reimbursed for private health care use (\%) & $\begin{array}{l}23 \\
\pm 0.1\end{array}$ & $\begin{array}{l}17 \\
\pm 0.1\end{array}$ & $\begin{array}{l}13 \\
\pm 0.2\end{array}$ & $\begin{array}{l}37 \\
\pm 0.2\end{array}$ & $\begin{array}{l}31 \\
\pm 0.2\end{array}$ & $\begin{array}{l}23 \\
\pm 0.2\end{array}$ \\
\hline \multicolumn{7}{|l|}{ Populations sociodemographic characteristics } \\
\hline Proportion of population aged $\geq 65(\%)$ & $\begin{array}{l}21 \\
\pm 0.1\end{array}$ & $\begin{array}{l}24 \\
\pm 0.1\end{array}$ & $\begin{array}{l}21 \\
\pm 0.3\end{array}$ & $\begin{array}{l}21 \\
\pm 0.1\end{array}$ & $\begin{array}{l}24 \\
\pm 0.2\end{array}$ & $\begin{array}{l}22 \\
\pm 0.2\end{array}$ \\
\hline Proportion of population with tertiary education (\%) & $\begin{array}{l}24 \\
\pm 0.2\end{array}$ & $\begin{array}{l}18 \\
\pm 0.2\end{array}$ & $\begin{array}{l}17 \\
\pm 0.3\end{array}$ & $\begin{array}{l}23 \\
\pm 0.2\end{array}$ & $\begin{array}{l}18 \\
\pm 0.2\end{array}$ & $\begin{array}{l}17 \\
\pm 0.3\end{array}$ \\
\hline \multicolumn{7}{|l|}{ Municipal characteristics } \\
\hline Degree of urbanization (\%) & $\begin{array}{l}80 \\
\pm 0.4\end{array}$ & $\begin{array}{l}70 \\
\pm 0.4\end{array}$ & $\begin{array}{l}57 \\
\pm 0.7\end{array}$ & $\begin{array}{l}80 \\
\pm 0.5\end{array}$ & $\begin{array}{l}70 \\
\pm 0.4\end{array}$ & $\begin{array}{l}65 \\
\pm 0.8\end{array}$ \\
\hline \multicolumn{7}{|l|}{ Other health-related factors } \\
\hline Morbidity index & $\begin{array}{l}94 \\
\pm 0.4\end{array}$ & $\begin{array}{l}112 \\
\pm 0.6\end{array}$ & $\begin{array}{l}120 \\
\pm 0.9\end{array}$ & $\begin{array}{l}95 \\
\pm 0.4\end{array}$ & $\begin{array}{l}112 \\
\pm 0.7\end{array}$ & $\begin{array}{l}120 \\
\pm 0.9\end{array}$ \\
\hline Pensioner's care allowance of recipients aged $\geq 65$ per 1000 inhabitants of the same age & $\begin{array}{l}108 \\
\pm 1\end{array}$ & $\begin{array}{c}144 \\
\pm 1\end{array}$ & $\begin{array}{l}169 \\
\pm 2\end{array}$ & $\begin{array}{l}171 \\
\pm 2\end{array}$ & $\begin{array}{l}221 \\
\pm 2\end{array}$ & $\begin{array}{l}248 \\
\pm 2\end{array}$ \\
\hline
\end{tabular}

All the differences between group averages (tested with ANOVA) were statistically significant $(p<0.0001)$ for every area-level factor SW $=$ southwestern cluster

$C=$ central cluster

$N=$ northern cluster

within the study period. The health centre areas in the northern cluster consistently had the highest level of ACSC rates, but their inhabitants were the least educated and had the highest coverage of morbidity. Further, these areas had the highest proportion of elderly people with limitations in ADL and the highest usage of PHC inpatient wards, but the lowest usage of private health care and private dental care. In all these characteristics, the southwestern cluster had the opposite. These findings describe the development of Finnish PHC in a surprisingly plausible manner: PHC in rural municipalities (where the need for care seems to be higher than elsewhere) was lagging behind developments in other parts of the country. This calls for further investments and novel solutions in the provision of rural PHC services.

\section{Strengths and weaknesses of the study}

This observational study described the geographical distribution and development over time of ACSC rates in Finland, which has not been previously studied. In comparison to previous studies assessing the geographical distribution of ACSC rates within other European countries, we assessed the rates of all three ACSC subgroups in the same model, which enabled a more comprehensive approach. However, the applied model is a grouping tool, which averages the characteristics of the several health centre areas observed. Also, there might exist health centre areas at the border of trajectories, whose grouping might change by just a slight change in ACSC rates. Thus, the evaluation of individual health centre areas or the intra-cluster variation among them requires further studies with more specific methods. This involves also the use of our results for direct evaluation of health centres, as ACSC rates can also be affected by factors other than the quality of PHC. Thus, the results need to be interpreted with caution. As we could not study associations between the explanatory factors and the ACSC hospitalisations at the individual level, we had to rely on descriptive analysis and cannot assess the causality between the area-level factors and ACSC rates. Thus, we cannot completely rule out the possibility of ecological fallacy. However, we calculated ACSC rates over a comprehensive time frame from individual hospitalisation data of Finnish registers, which have been shown to be of good quality [33]. As the included diagnose of unspecified pneumonia (J18.9) captures also hospitalisations that are unavoidable by currently available vaccinations, the vaccine-preventable ACSC rates needs to be interpreted with caution. With communityacquired pneumonias in the Finnish elderly 
Streptococcus pneumoniae is included in at least fifth of the radiologically-confirmed cases and influenza A approximately in a tenth [34]. Almost in the half of these cases pathogen remains unidentified. As the proportion of unspecified pneumonia in our hospitalisation data was larger than this, we interpreted that part of them were likely to be unrecognized pneumococcal diseases or influenza - an effect which scale we could not however ascertain. Further, we had to limit our analysis to population aged $\geq 20$ as we had no sociodemographic data for population under 20 years old. However, we assume this had only minor effect on the geographic distribution of ACSC rates as the majority of ACSC conditions occur in the elderly [21].

\section{Comparison with the literature}

Finland's decreasing trends in total ACSC rates are similar to those of Canada [35] and Denmark [36], but contrary to increasing trends in France [37], Sweden [38], and the UK [39]. However, direct comparison of the results from different studies and countries is not feasible since the definition of ACSC varies. We found only a few studies that applied a similar definition of ACSC between countries and within the same statistical model $[40,41]$. Even these studies, though, mainly analyse chronic conditions in order to retain comparability and avoid difficulties in interpreting the effect of different hospitalisation practices. Further, the elevated level of ACSC rates in rural areas is consistent with findings from Germany and Canada [42, 43], but it contradicts findings from Spain, where the distance to hospitals appears to decrease ACSC rates [44].

\section{Possible explanations for differences between clusters}

Finland's slight increase in vaccine-preventable ACSC rates occurred due to bacterial pneumonia and influenza. This is in line with previous studies reporting that other causes for vaccine-preventable ACSC have mostly disappeared in Finland due to high vaccination prevalence [45]. This applies also to hepatitis A and B, the incidence of which is quite low even though the vaccinations are only offered to high-risk groups [46, 47]. As the incidence of both bacterial pneumonia and influenza are high [34, 48, 49], increasing the currently low vaccination coverages $[50,51]$ could reduce such ACSC hospitalisations. The only data we had on the geographical distribution of vaccine coverage for these two diseases was for influenza among small children and the elderly in 2013, and thus we did not include these in the analysis. While co-morbidities and old age predispose people $[52,53]$ to pneumonias, it is likely that these risk factors contributed to the geographic disparities we observed. In 2010, Finland implemented a national infant vaccination program with a 10 -valent pneumococcal conjugate vaccine (PCV10), and it has since been shown to provide herd protection and decrease hospitalisations for both pneumococcal and all-cause pneumonias [51]. Thus, it is possible that the increase in vaccine-preventable ASCS that we observed will either stagnate or begin to decrease after 2013.

It is likely that the decrease in chronic ACSC rates occurred due to nationwide improvements in knowledge, screening, treatment, and follow-ups on chronic diseases [54-56]. This interpretation emphasises that different local approaches of PHC in Finland seem to play only a minor role in decreasing chronic ACSC rates, which is consistent with previous studies that access to $\mathrm{PHC}$ is not the main factor affecting ACSCs or its geographical distribution $[18,57]$. Though these findings support the suspected deterioration in PHC, part of the increase in relative disparities might have arisen from the different care pathways and hospitalisation criteria used in various Finnish hospital districts. The trajectories abided by the geographical borders of these districts: each district included health centre areas only in two consecutive clusters, with the exception of a single district in eastern Finland. Also, we assume that the differences in levels of SEP and the morbidity of inhabitants in health centre areas maintained the disparities among the different trajectories, but further research on this is needed.

The increase in acute ACSC rates in the northern cluster occurred due to hospitalisations for kidney and urinary tract infection (UTI) and dental conditions. Our finding on UTI hospitalisations is similar to that regarding the elderly in the UK [39], where it has been estimated that almost half of such admissions are incorrectly diagnosed [58]. One suggested reason for this inaccuracy, the usage of UTI as an acceptable cause for hospitalisations of frail older adults with an uncertain diagnosis [58], should also be considered in Finland. Thus, the increase in UTI hospitalisations likely reflects the accumulation of risk factors, such as an ageing population, diabetes and obesity $[59,60]$. Further, the limitations of ADL might mediate the link between UTIs [61] in the elderly and increased ACSC rates [23] through delays in accessing health centres. Our findings were in line with this possible interpretation: while the health centre areas in the central cluster had the largest proportion of elderly inhabitants, those in the northern cluster suffered more often from limitations in ADL. The hospitalisations for dental conditions in the northern cluster began to increase in our data in 2002, when Finland implemented an oral health care reform that removed age limitations on both access to Public Dental Services (PDS) and reimbursements for private dental care [62]. This reform increased the demand of PDS [62], but not of the private dentists [63]. It is likely that the observed geographic disparities resulted both from a 
previously unmet need for dental care by adults unable to access the private services at their own expense in the northern cluster and from a deterioration in performance of a since overburdened PDS. Since the reform, PDS has received plenty of new working-aged and elderly users [64], mainly of low SEP and with a relatively high need for care $[65,66]$. Unsurprisingly, the initial state of oral health of PDS patients has been poorer after the reform [66]. There still exists an unmet need for oral health care that has a clear socioeconomic gradient: the risk of being a non-user increases with lower incomes [67].

For area-level factors, our findings supported the previously documented effect of both morbidity and SEP on ACSC rates: the health centre areas with high morbidity and low SEP also had a high level of ACSC rates [18, 22, 23]. The high usage of private health care providers, on the contrary, occurred in areas with low morbidity and high SEP. In Finland, these providers offer an alternative route to both GP and secondary care outpatient consultations, but they are located mainly in urban areas. As the reimbursements cover only a fraction of the consultation fee, this route benefits more those with higher SEP - thus, this factor appears to be an indirect SEP indicator. The disparities in the usage of PHC inpatient wards might relate to a reduction in the number of beds in elderly homes [68], leaving PHC no other options than to hospitalise those who would need only institutional social care. This assumption could be further supported by the high morbidity and limitations in ADL among the elderly in northern Finland as well as the previously mentioned possibility of inaccurate diagnostics for UTIs. One possibility is that the cost savings of institutional social care in recent decades have been partially translated into health care expenditures. However, further research on this is needed.

\section{Implications for clinicians and policy makers}

Our findings relate less to differences in local PHC health centres and more to bigger health policy decisions affecting nationwide developments. We observed increasing relative disparities that partly supported the hypothesised deterioration in PHC in Finland due to a lack of national stewardship and decentralization - these geographic disparities appeared to follow an uneven distribution of population characteristics for SEP and morbidity. Wilding et al. [69] estimate that those persons with a limiting long-term illness are less likely to move longer distances, and when doing so prefer rural or highly urbanised areas. Thus, the development of population characteristics in rural Finland is unlikely to change in the near future. This highlights the urgent need for novel solutions in providing PHC services to rural areas: the question of how to address selective depopulation in rural Finland and elevated health and social care needs among inhabitants in those areas remains unanswered. With further analysis it might be possible to apply ACSC rates as a tool to identify both well and poorly performing health centres - and to promote transfer of well-functioning care pathways and protocols between them.

\section{Unanswered questions and future research}

Due to the lack of individual data on SEP and co-morbidities, we were unable to give any estimates of their effect on geographical disparities in ACSC rates. Future studies need also to account for possible geographic disparities in ACSC rates of youth populations. Also, we were unable to provide any insights into on-going debates on the usage of ACSC rates as a PHC quality indicator - which necessitates data that follows patients across the boundaries of different health care systems and through care episodes for specified diseases. The possible association of elevated ACSC rates and a high usage of PHC inpatient wards should also be examined in further detail. Though we observed gender and geographical disparities for ACSC rates, we were unable to assess possible ethnic inequities. More research on this is needed in Finland, as there exists minorities whose need for care very likely exceeds those of the majority population [70].

\section{Conclusions}

The performance of PHC in Finland seemingly developed rather well between 1996 and 2013, mainly due to a substantial reduction in the number of hospitalisations for chronic ACSC conditions. Relative geographic disparities mainly increased, partly supporting the hypothesised slow deterioration in PHC quality. The accumulation of health problems associated with an ageing population appeared to burden rural areas, highlighting the need for both further investments and novel solutions in the provision of health care services. The trajectory analysis of rates of the three ACSC subgroups over time provided a broad and plausible picture on the development of PHC in Finland, which could still be refined with individual data on morbidity and socio-economic position.

\section{Additional files}

\section{Additional file 1: The list of ACSC conditions with definition} notes. (PDF $130 \mathrm{~kb}$ )

Additional file 2: Mean ACSC rates in health centre areas and estimates of the multi-trajectory model. (PDF $244 \mathrm{~kb}$ )

Additional file 3: The original protocol for the study. (PDF $92 \mathrm{~kb}$ )

\section{Abbreviations}

ACSC: Ambulatory care sensitive conditions; ADL: Activities of daily living; GBTM: Group-based trajectory modelling; PDS: Public Dental Services; PHC: Primary health care; SEP: Socioeconomic position; THL: National 
Institute for Health and Welfare, Finland; UTI: Kidney and urinary tract infection

\section{Acknowledgements}

We thank Kristiina Manderbacka for her excellent contributions to both the planning and data collection of this study as well as comments on the first draft of the manuscript.

\section{The original protocol for the study}

Additional file 3

\section{Authors' contributions}

Every author contributed to the conception and design of the study as well as to the interpretation of the results and revision of the manuscript. Also, MS contributed to the data collection and drafted the manuscript, SL and MA contributed to the data collection and performed the statistical analysis, and IK coordinated the study. All authors have read and approved the final manuscript.

\section{Funding}

This work was supported by the Academy of Finland (project numbers 277 939 and 312 708), NordForsk (project number 74637), the Emil Aaltonen Foundation, the Health Centre of the City of Helsinki, the City of Helsinki Urban Facts, the Finnish General Practice Foundation and General Practitioners in Finland. However, they were not involved in the study design, data collection, findings or decision to publish. The authors would like to thank the funders for the financial support.

\section{Availability of data and materials}

The data that support the findings of this study are available from the National Institute for Health and Welfare (THL), but restrictions apply to the availability of these data, which were used under license for the current study, and so are not publicly available. Data are however available from the authors upon reasonable request and with permission of THL.

\section{Ethics approval and consent to participate}

Research Ethics Committee of the National Institute for Health and Welfare (THL) has approved this study. Consent to participate was not applicable the study group assessed pseudonymised data from routinely collected registers and did not handle personal information at any point. The registry administrator, THL, approved the usage of register data and the authorities of Statistics Finland performed the pseudonymisation.

\section{Consent for publication}

Not applicable.

\section{Competing interests}

The authors declare that they have no competing interests.

\section{Author details}

${ }^{1}$ Social and Health Systems Research Unit, National Institute for Health and Welfare, P.O. Box 30, 00271 Helsinki, Finland. ${ }^{2}$ Department of General Practice and Primary Health Care, Network of Academic Health Centres, University of Helsinki, Helsinki, Finland. ${ }^{3}$ Health Stations, Department of Social Services and Health Care, City of Helsinki, Finland. ${ }^{4}$ Faculty of Social Sciences, Tampere University, Tampere, Finland.

Received: 18 March 2019 Accepted: 20 August 2019

Published online: 04 September 2019

\section{References}

1. Erhola M, Jonsson PM, Pekurinen M, Teperi J. Access to care without queuing - Jonottamatta hoitoon [in Finnish]. Helsinki: National Institute for Health and Welfare; 2013.

2. Matveinen P, Knape N: Health Expenditure and Financing 2014. In: Official Statistics of Finland. Helsinki: National Institute for Health and Welfare; 2016: 55

3. Ailasmaa R: Personnel in local government health and social services 2014. In: Official Statistics of Finland. vol. 16. Helsinki: National Institute of Health and Welfare; 2015: 82.
4. Parmanne P, Ruskoaho J, Vänskä J. Statistics on physicians and the health care system 2014. Physicians in Finland. Finnish Medical Association; 2015.

5. Virtanen P, Oksanen T, Kivimäki M, Virtanen M, Pentti J, Vahtera J. Work stress and health in primary health care physicians and hospital physicians. Occup Environ Med. 2008;65(5):364-6.

6. Rotko T, Aho T, Mustonen N, Linnanmäki E: Bridging the Gap? Review into Actions to Reduce Health Inequalities in Finland 2007-2010 [in Finnish]. Helsinki: National Institute for Health and Welfare (THL); 2011.

7. Starfield B, Shi L, Macinko J. Contribution of primary care to health systems and health. Milbank Q. 2005;83(3):457-502.

8. Lehikoinen M, Arffman M, Manderbacka K, Elovainio M, Keskimäki I. Comparative observational study of mortality amenable by health policy and care between rural and urban Finland: no excess segregation of mortality in the capital despite its increasing residential differentiation. Int J Equity Health. 2016;15(1):1.

9. Kringos D, Boerma W, Bourgueil Y, Cartier T, Dedeu T, Hasvold T, Hutchinson A, Lember M, Oleszczyk M, Pavlic DR, et al. The strength of primary care in Europe: an international comparative study. Br J Gen Pract. 2013;63(616):e742-50.

10. OECD, Union E: health at a glance: Europe 2018; 2018.

11. Mattila Y. Major turning points or measured progress? A study of development trends in Finnish health care [in Finnish]. Helsinki: The Social Insurance Institution of Finland; 2011.

12. Saltman R, Busse R, Figueras J. Decentralization in health care: strategies and outcomes: McGraw-hill education (UK); 2006.

13. Satokangas M, Lumme S, Arffman M, Manderbacka K, Keskimäki I. ACSC trajectories for primary health care authorities in Finland in 1996-2013. Eur J Public Health. 2018;28(suppl_4):182-3.

14. Koskinen S, Härkänen T: THL's Morbidity Index 2012-2014. In: Statistical review. vol. 12. Helsinki: National Institute for Health and Welfare (THL). 2016.

15. Purdy S, Griffin T, Salisbury C, Sharp D. Ambulatory care sensitive conditions: terminology and disease coding need to be more specific to aid policy makers and clinicians. Public Health. 2009;123(2):169-73.

16. Purdy S, Griffin T, Salisbury C, Sharp D. Prioritizing ambulatory care sensitive hospital admissions in England for research and intervention: a Delphi exercise. Primary Health Care Res Dev. 2009;11(1):41.

17. Indicator Construction: Managing variation in emergency admissions. NHS Institute for Innovation and Improvement, 2016 [https://www.productivity. nhs.uk/Download/TechnicalDefinition/608].

18. Falster $M O$, Jorm LR, Douglas KA, Blyth FM, Elliott RF, Leyland AH. Sociodemographic and health characteristics, rather than primary care supply, are major drivers of geographic variation in preventable hospitalizations in Australia. Med Care. 2015;53(5):436-45.

19. Saver BG, Wang CY, Dobie SA, Green PK, Baldwin LM. The central role of comorbidity in predicting ambulatory care sensitive hospitalizations. Eur J Pub Health. 2014;24(1):66-72.

20. Page A, University of Adelaide. Public Health Information Development $U$, Australian Institute of $\mathrm{H}$, Welfare: Atlas of avoidable hospitalisations in Australia : ambulatory care-sensitive conditions. Adelaide, S. Aust.: Public Health Information Development Unit, the University of Adelaide; 2007.

21. Manderbacka K, Arffman M, Lumme S, Lehikoinen M, Ruuth I, Keskimäki I. Gauge for the quality of primary care? Ambulatory care-sensitive conditions in Finland 1996-2010 [in Finnish]. Finnish Med J. 2015;70(48):3298-304.

22. Eggli $Y$, Desquins B, Seker E, Halfon P. Comparing potentially avoidable hospitalization rates related to ambulatory care sensitive conditions in Switzerland: the need to refine the definition of health conditions and to adjust for population health status. BMC Health Serv Res. 2014;14:25-69636914-6925.

23. Schüssler-Fiorenza Rose SM, Stineman MG, Pan Q, Bogner H, Kurichi JE, Streim JE, Xie D. Potentially avoidable hospitalizations among people at different activity of daily living limitation stages. Health Serv Res. 2016.

24. SOTKAnet Statistic and Indicator bank. [ https://sotkanet.fi/sotkanet/en/index ].

25. Official Statistics of Finland: Disability benefits [e-publication]. [https://www. kela.fi/web/en/496].

26. Pace M, Lanzieri G, Glickman M, Zupanič T: Revision of the European standard population: report of Eurostat's task force: publications Office of the European Union; 2013.

27. Nagin DS, Odgers CL. Group-based trajectory modeling in clinical research. Annu Rev Clin Psychol. 2010;6:109-38.

28. Nagin DS, Jones BL, Passos VL, Tremblay RE. Group-based multi-trajectory modeling. Stat Methods Med Res. 2016;27(7):2015-23. 
29. Raftery AE. Bayesian model selection in social research. Sociol Methodol. 1995;25:111-63.

30. Burton $P$, Gurrin L, Sly P. Extending the simple linear regression model to account for correlated responses: an introduction to generalized estimating equations and multi-level mixed modelling. Stat Med. 1998;17(11):1261-91.

31. Jones BL, Nagin DS, Roeder KJSm, Research: A SAS procedure based on mixture models for estimating developmental trajectories 2001, 29(3): 374-393.

32. Official Statistics of Finland (OSF). Spatial data of Finnish municipalities. [http:// geo.stat.fi/geoserver/tilastointialueet/tilastointialueet:kunta4500k_2017/wfs]

33. Sund R. Quality of the Finnish hospital discharge register: a systematic review. Scand J Public Health. 2012;40(6):505-15.

34. Palmu AA, Saukkoriipi A, Snellman M, Jokinen J, Torkko P, Ziegler T, Kaijalainen T, Hausdorff WP, Verlant V, Kilpi TM. Incidence and etiology of community-acquired pneumonia in the elderly in a prospective populationbased study. Scand J Infect Dis. 2014;46(4):250-9.

35. Maria Sanchez SVJHJL, Hui J. CIHI survey: variations in Canadian rates of hospitalization for ambulatory care sensitive conditions. Healthcare Quarterly. 2008;11(4):20-2.

36. Schiotz M, Price M, Frolich A, Sogaard J, Kristensen JK, Krasnik A, Ross MN, Diderichsen F, Hsu J. Something is amiss in Denmark: a comparison of preventable hospitalisations and readmissions for chronic medical conditions in the Danish healthcare system and Kaiser Permanente. BMC Health Serv Res. 2011;11:347.

37. Weeks WB, Ventelou B, Paraponaris A. Rates of admission for ambulatory care sensitive conditions in France in 2009-2010: trends, geographic variation, costs, and an international comparison. Eur J Health Econ. 2016; 17(4):453-70.

38. Lofqvist T, Burstrom B, Walander A, Ljung R. Inequalities in avoidable hospitalisation by area income and the role of individual characteristics: a population-based register study in Stockholm County, Sweden. BMJ Quality Safety. 2014;23(3):206-14.

39. Bardsley M, Blunt I, Davies S, Dixon J. Is secondary preventive care improving? Observational study of 10-year trends in emergency admissions for conditions amenable to ambulatory care. BMJ Open. 2013;3(1).

40. Schiøtz M, Price M, Frølich A, Søgaard J, Kristensen JK, Krasnik A, Ross MN, Diderichsen F, Hsu J. Something is amiss in Denmark: a comparison of preventable hospitalisations and readmissions for chronic medical conditions in the Danish healthcare system and Kaiser Permanente. BMC Health Serv Res. 2011;11(1):347.

41. Thygesen LC, Christiansen T, Garcia-Armesto S, Angulo-Pueyo E, Martinez-Lizaga N, Bernal-Delgado E, Consortium E. Potentially avoidable hospitalizations in five European countries in 2009 and time trends from 2002 to 2009 based on administrative data. Eur J Pub Health. 2015;25(Suppl 1):35-43.

42. Burgdorf F, Sundmacher L. Potentially avoidable hospital admissions in Germany: an analysis of factors influencing rates of ambulatory care sensitive hospitalizations. Deutsches Arzteblatt Int. 2014;111(13):215-23.

43. Shah TI, Milosavljevic S, Bath B. Determining geographic accessibility of family physician and nurse practitioner services in relation to the distribution of seniors within two Canadian prairie provinces. Soc Sci Med. 2017;194:96-104.

44. Borda-Olivas A, Fernandez-Navarro P, Otero-Garcia L, Sanz-Barbero B. Rurality and avoidable hospitalization in a Spanish region with high population dispersion. Eur J Pub Health. 2013;23(6):946-51.

45. Rapola S. National immunization program in Finland. Int J Circumpolar Health. 2007;66(5):382-9.

46. Karvonen T, Auranen K, Kuusi M, Leino T. Epidemiology of hepatitis B infection in Finland: implications for immunisation policy. Vaccine. 2017: 35(3):412-8

47. Broman M, Jokinen S, Kuusi M, Lappalainen M, Roivainen M, Liitsola K, Davidkin I. Epidemiology of hepatitis a in Finland in 1990-2007. J Med Virol. 2010;82(6):934-41.

48. Jokinen C, Heiskanen L, Juvonen H, Kallinen S, Karkola K, Korppi M, Kurki S, Rönnberg PR, Seppä A, Soimakallio S, et al. Incidence of communityacquired pneumonia in the population of four municipalities in eastern Finland. Am J Epidemiol. 1993;137(9):977-88.

49. Jokinen $\mathrm{C}$, Heiskanen $\mathrm{L}$, Juvonen $\mathrm{H}$, Kallinen $\mathrm{S}$, Kleemola M, Koskela M, Leinonen M, Rönnberg P-R, Saikku P, Stén M, et al. Microbial etiology of community-acquired pneumonia in the adult population of 4 municipalities in eastern Finland. Clin Infect Dis. 2001;32(8):1141-54.
50. Blank PR, Schwenkglenks M, Szucs TD. Vaccination coverage rates in eleven European countries during two consecutive influenza seasons. J Infect. 2009;58(6):446-58.

51. Okasha O, Rinta-Kokko H, Palmu AA, Ruokokoski E, Jokinen J, Nuorti JP. Population-level impact of infant 10-valent pneumococcal conjugate vaccination on adult pneumonia hospitalisations in Finland. Thorax. 2018; 73(3):262-9.

52. Torres A, Peetermans WE, Viegi G, Blasi F. Risk factors for communityacquired pneumonia in adults in Europe: a literature review. Thorax. 2013; 68(11):1057-65.

53. Koivula I, Sten M, Makela PH. Risk factors for pneumonia in the elderly. Am J Med. 1994;96(4):313-20.

54. Manderbacka K, Arffman M, Lumme S, Lehikoinen M, Winell K, Keskimäki I. Regional trends in avoidable hospitalisations due to complications among population with diabetes in Finland in 1996-2011: a register-based cohort study. BMJ Open. 2016:6(8).

55. Haahtela T, Tuomisto LE, Pietinalho A, Klaukka T, Erhola M, Kaila M, Nieminen MM, Kontula E, Laitinen LA. A 10 year asthma programme in Finland: major change for the better. Thorax. 2006:61(8):663-70.

56. Kinnula VL, Vasankari T, Kontula E, Sovijarvi A, Saynajakangas O, Pietinalho A. The 10-year COPD Programme in Finland: effects on quality of diagnosis, smoking, prevalence, hospital admissions and mortality. Prim Care Respir J. 2011;20:178.

57. Vuik SI, Fontana G, Mayer E, Darzi A. Do hospitalisations for ambulatory care sensitive conditions reflect low access to primary care? An observational cohort study of primary care usage prior to hospitalisation. BMJ Open. 2017; 7(8):e015704.

58. Woodford HJ, George J. Diagnosis and Management of Urinary Tract Infection in hospitalized older people. J Am Geriatr Soc. 2009;57(1):107-14

59. Gibson W, Wagg A. Urinary tract infections in the elderly. Current Bladder Dysfunction Reports. 2015;10(3):222-6.

60. Foxman B. Urinary tract infection syndromes: occurrence, recurrence, bacteriology, risk factors, and disease burden. Infect Dis Clin N Am. 2014; 28(1):1-13.

61. Eriksson I, Gustafson Y, Fagerström L, Olofsson B. Prevalence and factors associated with urinary tract infections (UTIS) in very old women. Arch Gerontol Geriatr. 2010;50(2):132-5.

62. Niiranen T, Widström E, Niskanen T. Oral health care reform in Finland aiming to reduce inequity in care provision. BMC Oral Health. 2008;8(1):3.

63. Raittio E, Kiiskinen U, Helminen S, Aromaa A, Suominen AL. Dental attendance among adult Finns after a major oral health care reform. Community Dent Oral Epidemiol. 2014;42(6):591-602.

64. Linden J, Josefsson K, Widström E. Frequency of visits and examinations in the public dental Service in Finland - a retrospective analysis, 2001-2013. BMC Oral Health. 2017;17(1):138.

65. Widström E, Nihtilä A: Dental care of adults in health centres of large and medium-sized cities. [in Finnish]. Yhteiskuntapolitiikka-YP 2004, 69(4).

66. Raittio E: Use of oral health services and perceived oral health after the oral health care reform introduced during 2001-2002. Publications of the University of Eastern Finland. Dissertations in Health Sciences., no 345: The University of Eastern Finland; 2016.

67. Kallio J, Kallio J, Pesonen T, Rahkonen O, Murtomaa H: Non-use of dental services: could there be some other reason than just healthy teeth? [in Finnish]. Yhteiskuntapolitiikka-YP 2013, 78(1).

68. Arajärvi M, Kuronen R. Home care and housing services of social services department in 2016 - Kotihoito ja sosiaalihuollon laitos- ja asumispalvelut 2016 [in Finnish]. Helsinki: National Institute of Health and Welfare; 2017.

69. Wilding S, Martin D, Graham M. How far is a long distance? An assessment of the issue of scale in the relationship between limiting long-term illness and long-distance migration in England and Wales. Popul, Space Place. 2018;24(2):e2090.

70. Cacciani L, Agabiti N, Davoli M, Dalla Zuanna T, Canova C: Avoidable Hospitalization among Migrants and Ethnic Minorities in Developed Economies. In: Access to Primary Care and Preventative Health Services of Migrants. edn. Edited by Rosano A. Cham: Springer International Publishing; 2018: 67-81.

\section{Publisher's Note}

Springer Nature remains neutral with regard to jurisdictional claims in published maps and institutional affiliations. 